\title{
Achievement Goal Promotion at University: Social Desirability and Social Utility of Mastery and Performance Goals
}

\author{
Céline Darnon \\ Université Blaise Pascal
}

\author{
Benoît Dompnier and Florian Delmas \\ Université Pierre Mendès France
}

\author{
Caroline Pulfrey and Fabrizio Butera \\ Université de Lausanne
}

\begin{abstract}
The present research examines the ambivalence of achievement goal promotion at university, and more specifically in the psychology curriculum. On the one hand, psychology teachers explicitly encourage mastery but not performance (neither approach nor avoidance) goals. On the other hand, the selection process encourages the endorsement of not only mastery but also performance-approach goals. In fact, it would seem that both performance-approach and mastery goals are valued in a university context. Two pilot studies verified the above assumptions. Subsequently, Experiments 1, 2, and 3 showed that each of these goals corresponds to different aspects of social value. Indeed, high endorsement of mastery goals was associated with being judged as both likable (social desirability) and likely to succeed (social utility). High endorsement of performance-approach goals enhanced social utility judgments but reduced perceived likability. Performance-avoidance goals only enhanced perceived likability. The discussion focuses on the 2 functions of university, namely education (apparent in the official discourse of teachers) and selection (apparent in the university structure), and on the perceived value of achievement goals.
\end{abstract}

Keywords: achievement goals, university, social desirability, social utility, social value

During the last decade, research on motivation at university level has been largely dominated by achievement goal research. In this area, two main goals are usually described (e.g., Dweck, 1992; Nicholls, 1984): Mastery goals correspond to the desire to acquire knowledge, to learn. Performance goals on the other hand correspond to the desire to perform well compared with others. More recent models of achievement goals (Elliot, 1997, 1999; Elliot \& Harackiewicz, 1996) have divided performance goals into performanceapproach goals (trying to outperform others) and performanceavoidance goals (trying not to perform more poorly than others). Research has shown that mastery goals are associated with many positive outcomes (e.g., task interest, deep studying, efforts; for reviews, see Barron \& Harackiewicz, 2000; Dweck, 1986; Pintrich \& Schunk, 2002; Urdan, 2004). Performance-avoidance goals have been shown to lead to many maladaptive outcomes (e.g., low performance, low interest, self-handicapping). Performanceapproach goals, however, yield mixed results. On the one hand,

Céline Darnon, Laboratoire de Psychologie Sociale et Cognitive, Université Blaise Pascal, Clermont-Ferrand, France; Benoît Dompnier and Florian Delmas, Laboratoire Inter-universitaire de Psychologie, Université Pierre Mendès France, Grenoble, France; Caroline Pulfrey and Fabrizio Butera, Université de Lausanne, Lausanne, Switzerland.

We wish to express our gratitude to Charles Judd and Sandrine Redersdorff for comments on previous versions of this article. This work was supported by the Swiss National Science Foundation.

Correspondence concerning this article should be addressed to Céline Darnon, Laboratoire de Psychologie Sociale et Cognitive, Université Blaise Pascal, 34, Avenue Carnot, 63037 Clermont-Ferrand Cedex, France. E-mail: celine.darnon@univ-bpclermont.fr these goals lead to some negative outcomes (e.g., surface learning, low persistence after failure, negative affects), but on the other hand they also predict some positive outcomes, including academic achievement (e.g., Elliot \& Church, 1997; Harackiewicz, Barron, Carter, Lehto, \& Elliot, 1997; Harackiewicz, Barron, Tauer, Carter, \& Elliot, 2000; Pintrich, 2000; for a review, see Harackiewicz, Barron, Pintrich, Elliot, \& Thrash, 2002).

Most of the time in achievement goal research, goals are studied as independent variables predicting various outcomes. However, researchers agree on the fact that goals are malleable and highly dependent on the context and on classroom goal structure (see Ames, 1992; Blumenfeld, 1992; Meece, Anderman, \& Anderman, 2006; Urdan, 2004). This is probably why researchers often advise teachers on the goals that should be promoted (or not) in classrooms. Certainly because of the numerous positive outcomes that have been associated with mastery goals and the "risk" that performance goals might represent, most of the time, researchers recommend the promotion of mastery goals and discourage the use of performance goals (both approach and avoidance) in classrooms (e.g., Ames, 1992; Brophy, 2004, 2005; Dweck, 1986; Dweck \& Sorich, 1999; Maehr \& Midgley, 1991; Meece et al., 2006; Pintrich, 2003; Urdan \& Turner, 2005).

Thus, research is fairly consistent when it comes to deciding which goals should be promoted in classrooms, namely mastery goals, and which goals should not, namely performance (approach and avoidance) goals. However, does institutional goal promotion at university match these recommendations? And how do university students value mastery and performance goals? These questions are extremely important, because they refer to the ability of students to differentiate and assess the goals put forward by the 
institution of which they are members. The purpose of the present article is to address this question in the context of psychology departments, where most research on achievement goals has been conducted in the past.

\section{Institutional Discourse: Promotion of Mastery but Not Performance Goals}

Many factors have led us to think that mastery goals-but not performance goals - should be particularly valued in teachers' discourse. First, as mentioned earlier, the promotion of mastery and not performance goals is consistently recommended by researchers. There should be no reason, then, for teachers not to follow these recommendations, especially when it comes to psychology professors, who are aware of this research, and who are the focus of this particular set of studies. Moreover, Dweck and her colleagues have largely demonstrated that mastery goals correspond to an incremental view of intelligence (i.e., the belief that the level of intelligence can change) whereas performance goals correspond to a fixed view of intelligence (i.e., the belief that one has a certain amount of intelligence and that there is not much one can do to change it; Dweck, 1999). The incremental conception of intelligence is coherent with the belief that one can change and progress with education, and this view should, in this sense, be more in line with the role of teachers (i.e., education) than a fixed view. This is probably the reason why some researchers argue that mastery goals and not performance goals should match teachers' ideology. As Urdan (1997) pointed out, "Goal theory . . represents the point where empirical evidence and political ideology meet" (p. 120), going on to say that "proponents of a task goal orientation" (task goal orientation corresponds to mastery goals) "argue that classroom school level practices that highlight ability differences among students and operate in a competitive, limited rewards system are not just educationally unsound, but they are unfair and undemocratic" (p. 120). In the same vein, Nicholls (1989) presented the promotion of task goals as "ethically" more desirable and qualified ego goals (i.e., performance goals) as "unfortunate and cynical approaches to academic life" (p. 102).

Bearing this in mind, it is therefore not unreasonable to assume that in psychology classes mastery goals are likely to be promoted and performance-approach and performance-avoidance goals less so. Of interest, indirect evidence is provided by a robust and recurring result in the literature on self-set goals at university: In this body of research conducted in a university setting, most of the time with psychology students, the reported level of mastery goal endorsement is generally fairly high. On the other hand, the reported level of performance-approach and performanceavoidance goal endorsement is quite low (e.g., Darnon, Muller, Schrager, Pannuzzo, \& Butera, 2006; Elliot \& Church, 1997; Elliot \& McGregor, 1999, 2001; Van Yperen, 2006). This result is also consistent with the view put forward by Brophy (2005), who contends that performance goals are very seldom endorsed spontaneously in the classroom and are, in his terms, "low incidence events." It thus seems that students strongly endorse mastery goals but weakly endorse performance goals, in line with the view on achievement goals that is likely to be officially promoted at university.

\section{Institutional Practice: Promotion of Mastery and Performance-Approach Goals}

Another analysis of the university system leads, however, to different predictions concerning the value and promotion of the different goals. Some sociologists have conducted extensive research on educational systems and have pointed out that in Western countries, educational institutions, which include universities, have taken up the structuring role of assigning pupils and students to "the place where they belong" in society by selecting them in such a way as to reproduce the social inequalities typical of liberal societies (Duru-Bellat, 1996, 2006; see also Bourdieu, Passeron, \& Nice, 1990; Dubet \& Duru-Bellat, 2004). It is worth noting that Deutsch put forward a similar argument in his analysis of the selective role of the grading system (Deutsch, 1979). This analysis is also consistent with some economic analyses (see Arrow, 1973). According to these researchers, university serves as a filter designed to determine which place one may occupy in the workplace (see also Lamarche, 2006). Indeed, many students enroll every year at university, especially in the many countries, such as France, Italy, and Switzerland, where the only requirement for entering university is to have passed the high school final comprehensive exam, which is generally not terribly selective. However, these large numbers of students will be heavily reduced before they reach the bachelor's or master's degree graduation level. A survey carried out by the Organization for Economic Co-operation and Development (OECD) on "survival rates" pointed out that on average one third of students in OECD countries fail to make the grade before graduation, with Italy, Sweden, and Austria at the bottom end (around 50\%); the United States, the Netherlands, Denmark, Australia, Mexico, and Germany around the OECD average; and Ireland, Turkey, and Japan at the top end (around $15 \%$; OECD, 2006). Thus it appears that the role of university is not only to educate people but also to detect who, among the millions of students who enroll every year, are the best students, those who most "deserve" a degree. The aim of university is therefore not only to teach students skills and knowledge (the educational function, or the "cultural and ideological function" in Lamarche's [2006] terms) but also to select and classify people on the basis of their competence or merit (the selective function; see Duru-Bellat, 1996). If the first of these aims is firmly based on values of equality (giving every student a basic knowledge), the latter, on the contrary, is an expression of the perpetuation of differences among people (giving every student the chance to demonstrate that he or she is among the best students).

Students know very well that the university selection process is not without consequences. Indeed, the academic level one reaches has a significant influence on the kind of job one can get later on. Not only does it determine the amount of money one makes, but it also affects one's personal status, power, and value in society (Dubet \& DuruBellat, 2004). This means that if students understand this system well, they might infer that in order to succeed they not only have to learn and improve their skills, they also have to make it through the "filter," that is, to perform better than their fellow students. In other words, success at university not only explicitly requires learning (the educational function) but also, implicitly, requires getting better grades than others (the selection function). As a consequence of this double function, then, university might, in reality, be promoting not only mastery but also performance-approach goals. 
It is worth noting that in goal research, Nicholls (1984) very early argued that performance goals correspond to a definition of competence in terms of social comparison between oneself and others. In line with this idea, a great deal of research has shown that, indeed, assessment that emphasizes social comparison (Ames, 1984; Butler, 1987, 2006), the normative component of grading (Butler \& Nisan, 1986; Covington, 1992; Covington \& Omelich, 1984), and competition (Butler \& Kedar, 1990) are all factors that enhance performance goals (for reviews, see Ames, 1992; Brophy, 2004; Maehr \& Midgley, 1991; Meece et al., 2006). These factors are inseparable from the function of selection and are highly present in most educational systems including universities. Further support for this idea comes from recent research. Darnon, Butera and Harackiewicz (2007) experimentally induced in university psychology major students the endorsement of either mastery or performance-approach goal and then compared them with a control group for whom no specific goal was induced. Results indicated that in the control group the pattern of learning outcomes was very close to that obtained in the performance-approach goal condition. Kaplan (2004, Study 1) found similar results, showing that a control group yielded similar effects to the performanceapproach goal condition. In the same vein, Ames and Felker (1979), in a study comparing competitive, cooperative, and individual reward structures, found that the control group (an individual group structure) appeared to be equivalent to the competitive group structure. Taken together, these results support the argument that in its functioning, the university system is likely to value and promote the endorsement of not only mastery goals but also performance-approach goals.

\section{Two Components of Social Value}

Although this reasoning implies that both performanceapproach and mastery goals might somehow be valued in a university context, it does not imply that their value is identical. On the one hand, mastery goals match the discourse and explicit recommendations of teachers, whereas performance-approach goals do not. On the other hand, both the academic structure of the university itself and, in a more indirect way, its selection function value the adoption of not only mastery but also performanceapproach goals. Thus, it can be expected that mastery and performance-approach goals are not valued for the same reasons.

The literature on social judgment sheds light on this point. Indeed, five decades of research have shown that two dimensions seem to organize people's perceptions of people and objects (for a recent review, see Judd, James-Hawkins, Yzerbyt, \& Kashima, 2005). Osgood and his colleagues, in their seminal work on the semantic differential (Osgood, 1962, 1969; Osgood, Suci, \& Tannenbaum, 1957), pointed out that the connotative meaning of words could be organized at least along two dimensions: evaluation (positive vs. negative) and dynamism (powerful/active vs. powerless/passive). Such a bidimensional structure has also been observed in research on implicit personality theories (Rosenberg, Nelson, \& Vivekananthan, 1968; Rosenberg \& Sedlak, 1972; Vonk, 1993). The first dimension relates to what makes someone likable or unlikable, socially and morally attractive or unattractive, and includes traits such as nice, likable, aggressive, and selfish. Various researchers refer to this dimension as "social desirability" (Beauvois, 2003; Dubois \& Beauvois, 2005; Rosenberg et al.,
1968), "other-profitability" (Peeters, 1992, 2002), "morality" (Reeder \& Brewer, 1979; Wojciszke, 1997, 2005), "warmth" (Fiske, Cuddy, Glick, \& Xu, 2002; Judd et al. 2005), or "friendliness" (Wiggins, 1979). The second dimension generally includes traits such as competent, smart, and idiot and has been defined by several researchers as "competence" (Fiske et al., 2002; Judd et al., 2005; Reeder \& Brewer, 1979; Wojciszke, 1997, 2005), "selfprofitability" (Peeters, 1992, 2002), "intellectual desirability" (Rosenberg et al., 1968), "dominance" (Wiggins, 1979), or "social utility" (Beauvois, 2003; Dubois \& Beauvois, 2005). The existence of these two dimensions in social judgment has been documented in different areas: stereotypes and intergroup relations (Fiske et al., 2002; Judd et al., 2005), perception of occupations (Cambon, 2002; Le Barbenchon, Cambon, \& Lavigne, 2005), scholastic judgments (Dompnier, Pansu, \& Bressoux, 2007), social norms (Cambon, Djouari, \& Beauvois, 2006; Devos-Comby \& Devos, 2001; Dubois \& Beauvois, 2005), person perception (Reeder \& Brewer, 1979; Wojciszke, 1997, 2005), and personality assessment (Wiggins, 1979). Among the various bidimensional conceptions of person attributes, the approach of Beauvois and Dubois (Beauvois, 2003; Dubois \& Beauvois, 2005) seems particularly relevant to the problem of determining in what way goals are valued at university. According to these researchers, social value can be divided into two components: social desirability and social utility. Social desirability refers to individuals' capacity to satisfy the various motivations of the members of a given social group, and hence the degree to which they are liked. Social utility refers to individuals' capacity to satisfy the functional requirements of a given social environment or organization, and consequently the degree to which they can succeed within this social environment or organization.

Let us now examine to what extent the above-mentioned two components of social value (social desirability and social utility) are related to the endorsement of achievement goals. As already pointed out, mastery goals are promoted in the discourse of teachers. Thus, the student who strongly endorses mastery goals should be someone who fulfills teachers' motivations and aims and will consequently be perceived as someone who is liked by teachers. This should not be the case for performance-approach goals, which are not valued by teachers in their manifest discourse. In Beauvois and Dubois's terms, mastery goal endorsement should make a student "socially desirable" in the eyes of teachers, whereas performance-approach goals should not. This hypothesis is in line with the results obtained in a recent study, where Pekrun, Elliot, and Maier (2006) found a positive correlation between social desirability and mastery goals but not performance-approach goals (for which the correlation was negative although nonsignificant).

As far as social utility is concerned, the selection processes that a student has to go through in his or her university career implicitly indicates to students that in order to succeed, they not only have to improve their knowledge but they also have to get better grades than other students. Thus, not only mastery goals but also performance-approach goals are functional at university, which implies that mastery and performance-approach goals should both be characterized by a high degree of social utility.

What about performance-avoidance goals? To the extent that these goals do not create the opportunity for positive differentiation from another person, there are no reasons to expect them to be high in social utility. Moreover, given that there is a high consensus among researchers that performance-avoidance goals result in 
negative outcomes (e.g., Elliot \& Church, 1997; Elliot \& McGregor, 1999; Harackiewicz et al., 2002; Midgley \& Urdan, 2001), there are few reasons to expect teachers to promote such goals in their classes. Thus, performance-avoidance goals should be low in both social desirability and social utility.

\section{Overview and Hypotheses}

This set of experiments tests the general hypothesis that mastery goals and performance-approach goals are valued at university, at least in psychology curricula, but that the type of social value attributed to them is not the same. More precisely, the above analysis points to an ambivalence in goal promotion. As discussed above, it seems that mastery goals are in line with the discourse of researchers and teachers, whereas performance-approach goals are not. However, both mastery and performance-approach goals are an appropriate response to the organizational structure of the university and especially its selection function. In this respect, we hypothesize that (a) mastery goals should be high both in social desirability and in social utility; (b) performance-approach goals should be low in social desirability but high in social utility; and (c) performance-avoidance goals should be high neither in social desirability nor in social utility.

In a first pilot study, we tested the assumption that in their discourse, psychology university teachers promote mastery but not performance goals (neither performance-approach nor performance-avoidance). Then a second pilot study was designed to find out whether, in spite of this discourse, both performance-approach and mastery goals are valued by psychology students. The two pilot studies tested important assumptions and are therefore reported in some detail. The three experiments then tested the hypothesis that mastery, performance-approach, and performanceavoidance goals correspond to different components of social value. In Experiment 1, participants were asked to answer an achievement goal questionnaire with different self-presentation strategies, namely, to appear as likable versus as likely to succeed. In Experiments 2 and 3, participants were asked to assess the likability versus probability of success of fictitious participants who endorsed each of the three achievement goals either strongly or weakly. In Experiment 2, the three goals were evaluated separately, whereas in Experiment 3, they were orthogonalized.

\section{Pilot Study 1}

It has been argued that mastery goals are valued and promoted in psychology teachers' discourse whereas performance goals (either performance-approach or performance-avoidance) are not. The first step, before going any further, was to make sure that this assumption corresponds to the teachers' actual discourse.

\section{Method}

Participants. Twenty-two French university psychology teachers of various psychology-related topics, such as neuropsychology, clinical psychology, and social psychology, participated in this study. They were recruited on the basis of the fact that they taught psychology to university students. There were 9 women and 13 men, with a mean age of 35.68 years.
Procedure and materials. A questionnaire was sent to professors via the psychology department faculty lists of two French universities. In this questionnaire, teachers were asked to report what goals they considered important to communicate to students in their classes. More specifically, they were asked to report how much they usually try, in their classes, to underline the importance for students "to perform well compared to others," "to get good ranks," and "to get better grades than others" for performanceapproach goals $(\alpha=.82)$; "to learn as much as possible," "to understand what is taught," and "to master what is taught" for the mastery goals ( $\alpha=.16$ ); "not to perform poorly compared to others," "not to get worse grades than others," and "not to get bad ranks" for performance-avoidance goals $(\alpha=.88)$. Answers could range from 1 (not at all) to 7 (very much). In the case of mastery goals, the low alpha value is the consequence of the low variance in participants' responses on the three items. Indeed, on Item 2, all participants answered 6 or 7, and on Item 3, only 1 of them did not answer 6 or 7 .

\section{Results}

Mean goal promotion appeared to be $6.24(S D=0.53)$ for mastery goals, $1.77(S D=0.86)$ for performance-approach goals, and $2.24(S D=1.23)$ for performance-avoidance goals. Because of the low variance on some scores, Wilcoxon tests were performed to examine differences. The results indicate that the mean score for mastery goal promotion was significantly higher than that for performance-approach goal promotion, $Z(22)=4.11, p<$ .001 , and performance-avoidance goal promotion, $Z(22)=4.11$, $p<.001$. The mean score for performance-avoidance goal promotion was superior to that of performance-approach goal promotion, $Z(22)=2.11, p<.04$. Thus, in line with the recommendations of achievement goal researchers, teachers try to focus on promoting mastery goals in psychology classes more so than the two performance goals. Teachers do not try to promote performance-avoidance goals, and performance-approach goals even less.

\section{Pilot Study 2}

The aim of the second pilot study was to test the idea that both mastery and performance-approach goals are viewed by psychology students as a way to attain a certain social value in the eyes of their teachers. Participants were instructed to answer the achievement goal questionnaire in such a way as to generate a positive image of themselves (self-enhancement strategy) versus a negative image of themselves (self-depreciation strategy). If it is true that endorsement of these goals may be used to induce positive social value, then endorsement of the goals should vary according to the self-presentation condition-that is, higher endorsement in the self-enhancement than in the self-depreciation condition. The selfenhancement versus self-depreciation instruction technique is based on the self-presentation paradigm (Dubois, 2000; Gilibert \& Cambon, 2003; Jellison \& Green, 1981) and has proved to be a highly effective tool in determining whether a particular selfpresentation strategy can be used to achieve positive evaluations.

Moreover, if it is true that students' perceptions of the social value of different achievement goals are a result of explicit and implicit goal promotion within the university context, then it is to 
be expected that the difference between the two self-presentation strategies should be higher for juniors (third-year students) than for freshmen (first-year students), the consequence of socialization (e.g., Guimond \& Palmer, 1996).

\section{Method}

Participants. Fifty-four French psychology students, 27 freshmen and 27 juniors, volunteered for this experiment. There were between 9 and 18 participants per condition, randomly assigned. This sample was composed of 46 women and 7 men ( 1 person did not report gender), with a mean age of 20.2 years for freshmen and 22.1 years for juniors. In this experiment, as in the others, the majority of the participants were women, which reflects the typical distribution of students in psychology departments. We tested for gender effects in Pilot Study 2, as well as in Experiment 3 (but not in the other experiments, where the number of men was very low), and found that the inclusion of gender as a factor did not significantly change any of the reported results.

Procedure and materials. The experiment was carried out during a regular social psychology class (for freshmen as well as for juniors). Each participant received a questionnaire that varied in terms of the self-presentation instructions preceding the questionnaire. The "self-enhancement" and "self-depreciation" instructions were based on the self-presentation paradigm (Dubois, 2000; Gilibert \& Cambon, 2003; Jellison \& Green, 1981) and adapted for this study. In the self-enhancement condition, the instructions were as follows:

As you fill in the following questionnaire we would like you to try to generate a good image of yourself, that is, to answer in such a way as to be judged in a positive way by your teachers. More specifically, as you indicate your level of agreement with each of the following propositions, you should be trying to generate a good image of yourself.

In the self-depreciation condition, the instructions were,

As you fill in the following questionnaire we would like you to try to generate a bad image of yourself, that is, to answer in such a way as to be judged in a negative way by your teachers. More specifically, as you indicate your level of agreement with each of the following propositions, you should be trying to generate a bad image of yourself.

After the instructions, achievement goal items were presented. These items were extracted from the French version of Elliot and McGregor's (2001) Achievement Goal Questionnaire (in its French version, validated by Darnon \& Butera, 2005). The performance-approach (e.g., "It is important for me to do better than other students"; $\alpha=.85$ ); mastery (e.g., "I want to learn as much as possible from this class"; $\alpha=.97)$, and performance-avoidance (e.g., "I just want to avoid performing poorly"; $\alpha=.80$ ) items were used. Participants had to report how important each of these items was for them on a scale ranging from 1 (not at all) to 7 (very much), of course by keeping in mind the specific self-presentation instructions.

\section{Results}

Overview of the analyses. Regression analyses were conducted to analyze the data. The academic level variable was coded
-1 for freshmen and 1 for juniors. The instruction variable was coded -1 for the self-depreciation condition and 1 for the selfenhancement condition. Therefore, the model contained three predictors: academic level, instruction, and the interaction between these two variables. In preliminary analyses, age and the interactions between age and the independent variables were entered in the analyses. These analyses revealed a main effect of age on one of the dependent variables. Thus, age was entered as a covariate. Because none of the independent variables was significantly correlated with age, however, the interaction between age and the independent variables was not retained in the final model (see Muller, Yzerbyt, \& Judd, 2008; Yzerbyt, Muller, \& Judd, 2004) Means and standard deviations are reported in Table 1.

Mastery goals. Regressing mastery goals on the model revealed two significant main effects and an interaction. The main effect of academic level, $B=-0.42, F(1,49)=9.5, p<.004$, $\eta^{2}=.16$, indicated that freshmen $(M=4.63 ; S D=2.04)$ reported endorsing mastery goals to a greater extent than juniors $(M=4.49$; $S D=2.45)$. Moreover, the main effect for self-presentation instructions, $B=2.05, F(1,49)=236.09, p<.001, \eta^{2}=.83$, indicated that when they tried to generate a positive image of themselves, students reported a higher level of mastery goals $(M=$ 6.12; $S D=0.74)$ than when they wanted to generate a negative image of themselves $(M=2.11 ; S D=1.42)$. The two main effects were, however, qualified by a significant interaction, $B=0.43$, $F(1,49)=10.43, p<.003, \eta^{2}=.18$. This interaction indicates that the higher the academic level was, the higher was the difference between the two self-presentation strategies.

Performance-approach goals. Performance-approach goals were regressed on the same model. These analyses revealed a main effect for self-presentation instructions, $B=0.63, F(1,49)=9.75$, $p<.004, \eta^{2}=.17$, indicating that students reported more performance-approach goals in the self-enhancement condition $(M=$ 3.66; $S D=1.54)$ than in the self-depreciation condition $(M=$ 2.38; $S D=1.56)$. The main effect of academic level was marginal, $B=0.40, F(1,49)=3.82, p<.06, \eta^{2}=.07$, and showed that freshmen $(M=2.63 ; S D=1.42)$ tended to report lower levels of performance-approach goals than juniors $(M=3.69$; $S D=1.73)$. However, in line with the hypotheses, the interaction between these two variables, $B=0.45, F(1,49)=5.01, p<.03, \eta^{2}=.09$, indicated that the difference between self-presentation conditions was larger for juniors than for freshmen.

Performance-avoidance goals. As far as performanceavoidance goals are concerned, the significant main effect of

Table 1

Goal Endorsement As a Function of University Level and Self-Presentation Condition (Pilot Study 2)

\begin{tabular}{|c|c|c|c|c|c|c|}
\hline \multirow{2}{*}{$\begin{array}{l}\text { University level } \\
\text { and condition }\end{array}$} & \multicolumn{2}{|c|}{$\begin{array}{l}\text { Mastery } \\
\text { goals }\end{array}$} & \multicolumn{2}{|c|}{$\begin{array}{l}\text { Performance- } \\
\text { approach } \\
\text { goals }\end{array}$} & \multicolumn{2}{|c|}{$\begin{array}{l}\text { Performance- } \\
\text { avoidance } \\
\text { goals }\end{array}$} \\
\hline & $M$ & $S D$ & $M$ & $S D$ & $M$ & $S D$ \\
\hline \multicolumn{7}{|l|}{ Freshmen } \\
\hline Negative image & 2.81 & 1.54 & 2.47 & 1.46 & 3.28 & 1.17 \\
\hline Positive image & 6.09 & 0.85 & 2.76 & 1.43 & 4.02 & 1.56 \\
\hline \multicolumn{7}{|l|}{ Juniors } \\
\hline Negative image & 1.19 & 0.34 & 2.26 & 1.77 & 1.81 & 0.75 \\
\hline Positive image & 6.15 & 0.65 & 4.41 & 1.22 & 4.20 & 1.28 \\
\hline
\end{tabular}


self-presentation instructions, $B=0.78, F(1,49)=18.49, p<$ $.001, \eta^{2}=.27$, indicated that students reported a higher level of performance-avoidance goals in the self-enhancement condition $(M=3.66 ; S D=1.52)$ than in the self-depreciation condition $(M=2.35 ; S D=1.53)$. The effect of academic level was marginal, $B=-0.32, F(1,49)=2.95, p<.10, \eta^{2}=.06$, and suggested that performance-avoidance goals tended to be reported more by freshmen than by juniors. More important, the interaction was significant, $B=0.41, F(1,49)=5.09, p<.03, \eta^{2}=.09$. Once again, this interaction indicated that the higher the academic level was, the larger was the difference between the two selfpresentation instruction conditions.

In sum, Pilot Study 2 indicates that the three goals (and not only mastery goals) are enhanced when one wants to be judged in a positive way by one's own teachers. Even though this effect appears for the three types of goal, effect sizes indicate that the effect is particularly large for mastery goals $\left(\eta^{2}=.83\right)$. Moreover, it confirms that these effects are likely to be due to goal promotion at the university as they are stronger for juniors-who have already spent at least 2 years in the institution-than for freshmenwho have just arrived at the institution (see Guimond \& Palmer, 1996).

This pilot study also allows us to specify the predictions about performance-avoidance goals. Indeed, given that performanceavoidance goals are unlikely to be useful for the selection process, they were not expected to be perceived as high in social utility. Moreover, Pilot Study 1 indicated that these goals are not encouraged by teachers. This point is consistent with the fact that most researchers have observed negative outcomes resulting from performance-avoidance goal endorsement and encourage teachers not to promote performance-avoidance goals in their classes. Thus, performance-avoidance goals were not expected to be high either in terms of social utility or in terms of social desirability. However, Pilot Study 2 indicated that these goals do, in fact, appear to be valued by university students, at least psychology majors. One possible interpretation is that performance-avoidance goals correspond to a modest view of oneself (e.g., "I just want to avoid performing poorly in this class"). Knowing that bragging is usually an important concern for students (R. V. Levine \& West, 1976; Muller \& Butera, 2004) and that it is socially desirable to present oneself as being modest (Hareli \& Weiner, 2000; Schlenker \& Leary, 1982), especially for women (Heatherington, Crown, Wagner, \& Rigby, 1989; Wosinska, Dabul, Whetstone-Dion, \& Cialdini, 1996), it seems reasonable to think that students (especially psychology students, who are mainly women) will try to appear as modest as possible when they want to give a positive image of themselves. If this is the case, then performance-avoidance goals should be perceived as a way to appear nice and likable (social desirability), although not as someone who is likely to succeed (social utility).

\section{Experiment 1}

Thus, the two pilot studies confirm that, on the one hand, mastery goals but not performance goals (neither performanceapproach nor performance-avoidance) are encouraged by psychology teachers (Pilot Study 1) but that, on the other hand, psychology students perceive the three goals (and not only mastery goals) as a way to generate a positive image of themselves in the eyes of their teachers (Pilot Study 2). These pilot studies illustrate the ambivalence inherent within the university system, at least in psychology, when it comes to achievement goals, especially performance-approach goals. Indeed, the official discourse encourages mastery goals and discourages performance-approach goals, as revealed by Pilot Study 1. However, the functioning of the university system implies that in order to achieve, one must not only learn (mastery goals) but also demonstrate one's abilities relative to others (performance-approach goals). Pilot Study 2 showed that these psychology students were aware that the three achievement goals can be effective in enhancing some sort of positive value in the eyes of teachers. Experiment 1 is the first of three experiments aimed at showing what components of social value underlie the endorsement of these three achievement goals.

As in Pilot Study 2, participants were asked to answer an achievement goal questionnaire with different self-presentation instructions. Two sets of instructions were designed to differentiate between social desirability and social utility, along with a control condition that had no instructions. As Pilot Study 2 had shown that the self-presentation effects were manifested more strongly by junior students, only juniors took part in Experiment 1. As discussed earlier, mastery goals match the teachers' discourse (cf. Pilot Study 1). They are therefore likely to be the goals a student will adopt in order to appear as someone who is nice and liked by teachers (social desirability). Performance-approach goals do not match this discourse and thus should not be publicly endorsed if students want to be liked by their teachers. On the other hand, as detailed earlier, achieving at university means not only learning and improving one's knowledge but also outperforming others. In this respect, wanting to appear as someone who is likely to succeed at university (social utility) might very well generate increased adherence to both mastery and performance-approach goals. Because of the social value of modesty discussed earlier, performance-avoidance goals are expected to be enhanced when one wants to be liked by one's teachers but should not be enhanced when one wants to appear as likely to succeed. To sum up, in line with our general hypothesis, we predict that (a) endorsement of mastery goals should be high in both social desirability and social utility conditions, higher than in the control condition; (b) endorsement of performance-approach goals should be high only in the social utility condition, higher than in the social desirability and the control conditions; and (c) endorsement of performanceavoidance goals should be high only in the social desirability condition, more so than in the social utility and control conditions.

\section{Method}

Participants. Forty-seven juniors in the psychology department of a French university volunteered for this experiment. Two participants were dropped from the analysis because of uncommon studentized deleted residuals (Judd \& McClelland, 1989). The final sample was composed of 45 juniors randomly assigned to the three conditions, resulting in between 14 and 16 people per condition. The whole sample was composed of women, with a mean age of 21.74 years.

Procedure and materials. Participants were asked to answer the achievement goal questionnaires $(\alpha=.89$ for performanceapproach goals; $\alpha=.87$ for mastery goals; and $\alpha=.79$ for performance-avoidance goals) after having received differing 
instructions. In the "standard" condition (the control group), participants were asked to answer spontaneously. Indeed, the questionnaire was presented similarly to the way it is presented in most achievement goal research. The instructions preceding the questionnaire were, "Please indicate your level of agreement with each of these statements." In the social desirability condition, the instructions were as follows:

We would like you to try to show you are a student who possesses all the qualities to make yourself popular with your teachers. More precisely, we'd like you to indicate your level of agreement with each of the following statements, with a view to presenting yourself as someone who is likely to be appreciated by others.

In the social utility condition, the instructions were as follows:

We would like you to try to show you are a student who possesses all the qualities to succeed at university, in the eyes of your teachers. More precisely, we'd like you to indicate your level of agreement with each of the following statements, with a view to presenting yourself as someone who is likely to succeed in his or her studies.

The rest of the procedure and materials were identical to those used in Pilot Study 2.

\section{Results}

Overview of the analyses. Regression analyses were conducted to test our hypotheses. The independent variable selfpresentation instructions had three levels. It was broken down into two orthogonal contrasts. These contrasts vary for each dependent variable so that the first contrast tests the specific prediction and the second contrast is the orthogonal contrast. Preliminary analyses revealed a main effect of age on one of the dependent variables. Moreover, the independent variable had more than two levels. Thus, age, and the interaction between age and the two contrasts, were entered as covariates (Muller et al., 2008). Means and standard deviations are presented in Table 2.

Mastery goals. As far as mastery goals are concerned, the two contrasts were as follows: In the first contrast, both the utility and the desirability conditions were coded 1 . The standard condition was coded -2 . The second contrast compared the desirability condition $(-1)$ with the utility condition (1; the standard condition was coded 0$)$. Regression analyses revealed that the first contrast was significant, $B=0.35, F(1,39)=6.8, p<.02, \eta^{2}=.15$, whereas the second was not $(B=-0.07, F<1)$.

Performance-approach goals. As far as performanceapproach goals are concerned, the two contrasts were as follows:

Table 2

Mean Goal Endorsement As a Function of Instructions (Experiment 1)

\begin{tabular}{|c|c|c|c|c|c|c|}
\hline \multirow[b]{2}{*}{ Condition } & \multicolumn{2}{|c|}{$\begin{array}{c}\text { Mastery } \\
\text { goals }\end{array}$} & \multicolumn{2}{|c|}{$\begin{array}{l}\text { Performance- } \\
\text { approach } \\
\text { goals }\end{array}$} & \multicolumn{2}{|c|}{$\begin{array}{c}\text { Performance- } \\
\text { avoidance } \\
\text { goals }\end{array}$} \\
\hline & $M$ & $S D$ & $M$ & $S D$ & $M$ & $S D$ \\
\hline Standard & 4.76 & 0.93 & 3.51 & 1.54 & 4.09 & 1.53 \\
\hline Social desirability & 5.86 & 1.38 & 3.76 & 1.33 & 5.24 & 1.42 \\
\hline Social utility & 5.83 & 1.22 & 4.48 & 1.53 & 4.08 & 1.80 \\
\hline
\end{tabular}

In the first contrast, the utility condition (coded 2) was compared with the desirability and standard conditions (each coded -1 ). The second contrast compared the standard condition (-1) with the desirability condition (1). Regression analyses revealed that the first contrast was significant, $B=0.34, F(1,39)=4.87, p<.04$, $\eta^{2}=.11$. The second was not significant $(B=0.19, F<1)$.

Performance-avoidance goals. As far as performanceavoidance goals are concerned, the two orthogonal contrasts were as follows: The first contrast compared the desirability condition (coded 2) with the utility and standard conditions (coded -1 each). The second contrast compared the standard condition (coded -1) with the utility condition (1). Regression analyses revealed that the first contrast was significant, $B=0.41, F(1,39)=4.52, p<.04$, $\eta^{2}=.10$, whereas the second was not $(B=-0.02, F<1)$.

\section{Discussion}

In line with the hypotheses, the results of the present experiment illustrate that the three goals do not correspond to the same kind of value. Mastery goals are valued in terms of both social desirability and social utility. Indeed students, both when they were asked to appear likable and when they were asked to appear as students likely to succeed, reported a higher level of agreement with mastery goals than students in the control condition. On the contrary, endorsement of performance-approach goals was not increased by the likability instructions, but these goals were, however, perceived as a means to present oneself as someone who has a good chance of academic success, that is, as goals high in social utility. Finally, performance-avoidance goals appeared to be endorsed only to achieve social desirability, in comparison with the social utility and control conditions. The latter result provides support for our interpretation in terms of modesty. Indeed, modesty usually enhances judgments of attractiveness (R. V. Levine \& West, 1976; Schlenker \& Leary, 1982) and is valued in friendship (Tice, Butler, Muraven, \& Stillwell, 1995); in other words, modesty enhances social desirability but not social utility (see also Dubois, 2000).

Taken together, the results of this experiment support the idea that psychology students, at least female psychology students, perceive a certain ambivalence in their teachers' attitudes toward achievement goals, and that they have learned to use goal endorsement strategically. There are, however, two limitations to our conclusions owing to the paradigm used in this experiment. First, although the self-presentation paradigm makes it possible to identify the different strategies that participants choose to influence another person's judgment, it does not indicate whether such strategies actually produce the expected effect on social judgment. Second, it is important to note that in the self-presentation paradigm, participants are personally involved in their answers. That means that the answers they give reflect not only the perceived social desirability and utility of goals but also other strategies one might use in one's own answers guided by motives other than attempting to exert a positive influence on teachers' perceptions (e.g., self-protection). Bearing this in mind, the judge's paradigm (Dubois, 2000; Gilibert \& Cambon, 2003; Jellison \& Green, 1981) provides us with a useful complement in the study of the social value of goals. Indeed, in the judge's paradigm, participants are asked to judge targets who are profiled in terms of their self-presentation strategy. This makes it possible to find out whether different selfpresentation strategies are indeed imbued with different components 
of social value, that is, whether they produce the expected effects on social judgment. Moreover, in the judge's paradigm, one has to assess another person. There is no direct implication of the self, and therefore the answers are more likely to be a direct reflection of social value. As a consequence, the use of the judge's paradigm represents a complement to Experiment 1, by allowing us to examine whether the results observed with the self-presentation paradigm can be replicated with an alternative tool designed to capture social value. This is the aim of Experiment 2.

\section{Experiment 2}

In the second experiment, the judge's paradigm (Dubois, 2000; Gilibert \& Cambon, 2003; Jellison \& Green, 1981) was used. Students were asked to judge a target (another student) who was supposed to have previously filled in the goal questionnaires. This fictitious participant was presented as having endorsed either to a large or a small extent one of the three types of goals. In the present experiment, one type of goal was presented per condition (see Experiment 3 for a simultaneous presentation). That is, participants could see the target's answers on only one scale, either the mastery goal scale, the performance-approach goal scale, or the performance-avoidance goal scale.

In line with the results of Experiment 1, we expected that the target who strongly endorses mastery or performance-avoidance goals should be judged as more likable (social desirability) than a target who weakly endorses these goals, more so than when goals are performance-approach goals. As far as social utility is concerned, the target who strongly endorses mastery or performanceapproach goals should be judged as more likely to succeed (social utility) than the target who weakly endorses these goals, more so than when goals are performance-avoidance goals.

\section{Method}

Participants. One hundred twenty-three junior psychology students attending a French university volunteered for this experiment. There were 109 women and 14 men, with a mean age of 22.24 years. They were randomly assigned to one of the six experimental conditions, resulting in between 17 and 23 people per condition.

Procedure and materials. Each participant received two questionnaires. The first one was presented as a questionnaire that had been previously filled in by another psychology student and con- tained three items. Depending on the condition, these three items were either the mastery goal items, the performance-approach goal items, or the performance-avoidance goal items (taken from the French version of Elliot \& McGregor's [2001] scale). The fictitious participant was supposed to have indicated to what extent each of these items was true for him (or her) on a 7-point scale ranging from 1 (not at all) to 7 (very much). The second independent variable was the degree of agreement with the statements, the target's answers being either high $(6,5$, and 6 were circled) or low (2, 3, and 2 were circled).

Participants were asked to study carefully the items and the answers the participants had circled. They were then told to look at the second questionnaire. On this second questionnaire participants read, "On the basis of the information you have just seen, please indicate to what extent you think that this student is likely to be judged by his/her teachers as ...," after which six traits were presented: "likely to succeed," "pleasant," "likable," "smart," "nice," and "competent." Participants were asked to answer on a scale ranging from 1 (not at all) to 7 (very much) for each of these traits.

\section{Results}

Factor analyses. First we conducted a factor analysis on the six judgment items. Principal axis factoring with Kaiser normalization was used. The analysis revealed two factors accounting for $64.7 \%$ of the variance. The first factor accounted for $48.3 \%$ of the variance and contained the three desirability items: likable, pleasant, and nice. The second factor included the utility items: likely to succeed, smart, and competent. It accounted for $16.4 \%$ of the variance. The items as well as their factor loading on each factor are presented in Table 3. The correlation between the two factors was .43. The two factor scores were used as dependent variables. The social desirability scores ranged from -2.52 to 2.14 . The utility scores ranged from -2.66 to 2.34 .

Overview of the analyses. Regression analyses were conducted on the social desirability and social utility scores. The model contained two independent variables. The first one was the type of goal presented, with three levels: mastery goals, performance-approach goals, and performance-avoidance goals. The first independent variable was broken down into two orthogonal contrasts for each variable. The second independent variable was the degree of endorsement of each goal, with two levels: high (coded 1) and low (coded -1). Because preliminary analyses

Table 3

Judgment Items and Their Factor Loading Using Principal Axis Factoring, Oblimin Rotation With Kaiser Normalization (Experiments 2 and 3)

\begin{tabular}{lccccc}
\hline & \multicolumn{2}{c}{ Experiment 2 } & & Experiment 3 \\
\cline { 2 - 3 } \multicolumn{1}{c}{ Item } & $\begin{array}{c}\text { Factor 1 (Social } \\
\text { Desirability) }\end{array}$ & $\begin{array}{c}\text { Factor 2 } \\
\text { (Social Utility) }\end{array}$ & & $\begin{array}{c}\text { Factor 1 (Social } \\
\text { Desirability) }\end{array}$ & $\begin{array}{c}\text { Factor 2 } \\
\text { (Social Utility) }\end{array}$ \\
\hline Nice & .84 & .01 & .94 & -.08 \\
Likable & .88 & -.09 & .86 & -.01 \\
Pleasant & .68 & .14 & .71 & .16 \\
Competent & .01 & .98 & .02 & .89 \\
Smart & .25 & .55 & .14 & .64 \\
Likely to succeed & -.08 & .64 & -.09 & .74 \\
\hline
\end{tabular}


revealed no effect of age, age was not retained in the final model. Thus, regression analyses contained five predictors: Contrast 1, Contrast 2, endorsement level, Endorsement Level $\times$ Contrast 1 , and Endorsement Level $\times$ Contrast 2. Means and standard deviations are presented in Table 4.

Social desirability. In line with the findings of Experiment 1, the hypothesis was that both mastery and performance-avoidance goals would be socially desirable, whereas performance-approach goals would not. Therefore, the first contrast compared these two conditions (coded 1 each) with the performance-approach condition (coded -2). The second orthogonal contrast compared mastery goals (1) with performance-avoidance goals $(-1)$.

Neither the main effect of each contrast, $B=-0.02, F<1$, for Contrast 1; $B=-0.007, F<1$, for Contrast 2, nor the main effect of endorsement level, $B=0.06, F<1$, was significant. However, there was a significant interaction between the first contrast and endorsement level, $B=0.14, F(1,117)=5.47, p<.03, \eta^{2}=.04$, showing that the higher the level of mastery and performanceavoidance goal endorsement was, the higher the target was scored on social desirability $(B=0.20)$, whereas the higher the level of performance-approach goal endorsement was, the lower the target was scored on social desirability $(B=-0.21)$.

Social utility. We hypothesized that both mastery and performance-approach goals would be high in social utility, higher than performance-avoidance goals. The first contrast thus compared these two conditions (coded 1 each) with the performanceavoidance condition (coded -2 ). The second contrast compared the mastery (1) with the performance-approach goal condition $(-1)$.

Regression analyses revealed no main effects of the two contrasts, $B=-0.06, F(1,117)=1.19, p=.28, \eta^{2}=.01$, for Contrast $1 ; B=0.10, F<1$, for Contrast 2 . They did, nevertheless, reveal a main effect of endorsement level, $B=0.33, F(1$, $117)=16.93, p<.001, \eta^{2}=.13$, indicating that in general, the higher the answer on the goal scales was, the higher was the perceived social utility. This main effect was, however, qualified by a significant interaction between Contrast 1 and endorsement level, $B=0.14, F(1,117)=5.50, p<.02, \eta^{2}=.04$, showing that higher levels of mastery and performance-approach goal endorsement were associated with a significantly higher social utility score ( $B=0.48)$, an effect not found for higher performance-avoidance goal endorsement $(B=0.06)$.

Table 4

Social Desirability and Social Utility of Mastery, PerformanceApproach, and Performance-Avoidance Goals (Experiment 2)

\begin{tabular}{|c|c|c|c|c|c|c|}
\hline \multirow{2}{*}{$\begin{array}{c}\text { Goal } \\
\text { endorsement }\end{array}$} & \multicolumn{2}{|c|}{ Mastery goals } & \multicolumn{2}{|c|}{$\begin{array}{l}\text { Performance- } \\
\text { approach goals }\end{array}$} & \multicolumn{2}{|c|}{$\begin{array}{l}\text { Performance- } \\
\text { avoidance } \\
\text { goals }\end{array}$} \\
\hline & $M$ & $S D$ & $M$ & $S D$ & $M$ & $S D$ \\
\hline \multicolumn{7}{|c|}{ Social desirability } \\
\hline High & 0.15 & 0.86 & -0.18 & 1.04 & 0.18 & 0.73 \\
\hline Low & -0.24 & 0.90 & 0.25 & 1.18 & -0.24 & 0.78 \\
\hline \multicolumn{7}{|c|}{ Social utility } \\
\hline High & 0.67 & 0.69 & 0.11 & 0.92 & 0.17 & 0.94 \\
\hline Low & -0.64 & 0.92 & -0.48 & 1.00 & 0.05 & 0.98 \\
\hline
\end{tabular}

It is worth noting that the interaction between the second contrast and endorsement level was marginal, $B=0.18, F(1,117)=$ 3.26, $p<.08, \eta^{2}=.03$. This interaction indicated that the effect in the mastery condition tended to be stronger $(B=0.65)$ than in the performance-approach condition $(B=0.30)$.

\section{Discussion}

The objective of the present experiment was to test the same hypotheses as those tested in Experiment 1 using a different and more diagnostic paradigm. Results indicated that the findings of Experiment 1 were conceptually replicated in Experiment 2. A target characterized by a high degree of endorsement of mastery and performance-avoidance goals was perceived as more likable (social desirability) than one who showed only limited agreement with these goals, an effect not found when the goals in question were performance-approach goals. It is interesting to note that the slope is negative for performance-approach goals, suggesting that not only were these goals not perceived as desirable, they were considered undesirable. Indeed, the target who strongly endorsed these goals was perceived as less likable than the target who weakly endorsed them. Although Experiment 1 did not show any differences between the social desirability instructions and the standard instructions in terms of performance-approach goal endorsement, the present finding is in line with the hypotheses and consistent with previous research. Notably, Green (2006) observed that in terms of achievement (social utility), a target high in competitiveness (a trait that is very close to performance-approach goals) was perceived more positively than a target low on this trait, whereas the reverse effect was observed for judgments relating to social relationships (social desirability). Moreover, as mentioned in the introduction and as argued, for example, by Urdan (1997), performance-approach goals have a poor degree of fit with the ideology and representation of teaching typical of psychology university teachers. This could explain why performance-approach goals are perceived as undesirable. In discussing the results of Experiment 2, a final observation is that a high level of performance-avoidance goal endorsement only enhanced perceived likability; it did not make students appear likely to succeed. This result is consistent with the results obtained in Experiment 1.

An important limitation has to be mentioned. In the present experiment, the target presented to participants was characterized by only one type of goal. One could argue that the pattern of results would have been different if participants had had the opportunity to evaluate the target not only on the basis of one type of goal but on the three types of goal simultaneously. Recent research on achievement goals (Barron \& Harackiewicz, 2001) has pointed out that although for a long time, mastery and performance goals were opposed and considered mutually exclusive, students can in fact pursue multiple goals at the same time. It would seem reasonable, therefore, to think that perceptions of endorsement of a certain goal might be related to the perceived degree of endorsement of another goal. One could argue, indeed, that the results obtained in Experiment 2 are due to the fact that in this experiment goals were presented independently of one another. It is possible that some goals are ambiguous enough to be perceived as more or less high in social desirability or social utility, depending on the extent to which other goals are endorsed at the same time. One possible hypothesis is that the positive effects of level of endorsement 
observed in Experiment 2 would appear only above a certain level of agreement with another goal.

Another possible hypothesis, the one we favor, is that the effects are strong enough to drown out the potential changes other goals might generate in the perception one has of the target. More specifically, we think that high mastery goals will lead to higher perceived social desirability and social utility than low mastery goals whatever the level of other goals. The same reasoning applies to the predicted effects of performance-approach and performance-avoidance goals. Indeed, we think that high performance-approach goals will lead to higher perceived social utility and lower perceived social desirability than low performanceapproach goals, again whatever the level of endorsement of other goals. Finally, we think that a target who endorses high levels of performance-avoidance goals will be perceived as more socially desirable than a target who endorses low levels of those goals, whatever the level of endorsement of other goals. In the third experiment, we contrasted the above two hypotheses, namely, examining interaction versus main effects.

\section{Experiment 3}

In Experiment 3, as in Experiment 2, the judge's paradigm was used. The main difference between the two experiments was that in the present experiment the participants could see how the target had responded to all three goal scales rather than only one of them. The experimental design was 2 (mastery goals: high, low) $\times 2$ (performance-approach goals: high, low) $\times 2$ (performanceavoidance goals: high, low).

\section{Method}

Participants. Two hundred twenty junior psychology students attending a French university volunteered for this experiment. Four participants appeared to be outliers owing to uncommon studentized deleted residuals (Judd \& McClelland, 1989) and were removed from the analyses. The final sample was therefore composed of 216 participants, 177 women and 38 men (1 person did not report gender), with a mean age of 22.55 years. Participants were randomly assigned to one of the eight conditions, resulting in between 24 and 29 people per condition.

Procedure and materials. The procedure was very close to that used in Experiment 2. The main difference was that in the present experiment, participants received the target's answers on the three goal scales. As in Experiment 2, target answers on each type of goal showed either high $(6,5$, and 6 were circled) or low (2, 3, and 2 were circled) levels of agreement with the statements. The target could therefore be high on the three goals, low on the three goals, high on two of the goals and low on the third goal, or high on one of the goals and low on the two others. Moreover, the order of goal presentation was counterbalanced. Given that three goals were involved in the present study, each type of goal was presented either in the first place on the target's questionnaire, in the second place, or in the third place. The six possible configurations were PAP-M-PAV; PAP-PAV-M; M-PAP-PAV; M-PAVPAP; PAV-M-PAP; and PAV-PAP-M. After having read the bogus participant's answers, participants were asked to answer the same questions as in Experiment 2.

A potential problem of the design was that conditions might differ in terms of credibility. More specifically, especially because goals are not independent from one another, one could expect some conditions (e.g., the one in which targets strongly endorse both performance-approach and performance-avoidance goals) to induce the image of a person who is particularly inconsistent. To check that point, two additional questions were included at the end of the questionnaire: Participants were asked to indicate whether they thought the answers given by the target were coherent and credible on 7-point scales. The two items were aggregated in a score of perceived coherence $(\alpha=.74)$.

\section{Results}

Factor analysis. As in Experiment 2, a factor analysis (principal axis factoring with Kaiser normalization) was conducted on the six judgment items. The analysis revealed two factors accounting for $66.7 \%$ of the variance. The first factor, which accounted for $47.7 \%$ of the variance, contained the desirability items, namely, likable, pleasant, and nice. The second factor, which accounted for $19 \%$ of the variance, included the utility items, namely, likely to succeed, smart, and competent. The items and their factor loadings are presented in Table 3. The correlation between the two factors was .39. As in Experiment 2, a score of social utility and a score of social desirability were created on the basis of the loadings on these two factors.

Overview of the analyses. Regression analyses were again conducted to test our hypotheses. In preliminary analyses, both the order of goal presentation and the interactions between order and the independent variables were included in the analyses. These analyses did not reveal any main effects of order or interactions between order and the independent variables. Thus, order was removed from the final model. Moreover, preliminary analyses did not reveal any main or interaction effect of age or gender, and thus, neither age nor gender was retained in the final model. In preliminary analyses, perceived coherence was also included in the model. This variable yielded significant main effects on both dependent variables. Moreover, the independent variables all had a significant effect on coherence. Thus, coherence, and the interactions between coherence and the other predictors, were included in the model (Muller et al., 2008; Yzerbyt et al., 2004). The regression model thus included 15 predictors: the three independent variables (endorsement of mastery, performance-approach, performance-avoidance) each coded 1 (high) and -1 (low), the three two-way interactions, the three-way interaction, perceived coherence (centered), and the interaction between each term and coherence. This model was regressed on the score of social utility and the score of social desirability. Means and standard deviations are presented in Table 5.

Social desirability. As far as social desirability is concerned, four main effects were observed. First, the main effect of coherence was significant and positive, $B=0.16, F(1,199)=13.91$, $p<.001, \eta^{2}=.07$. The more the target is perceived as coherent, the more positively he or she is judged in terms of social desirability. More important, as predicted, a main effect of mastery goal endorsement, $B=0.14, F(1,199)=4.78, p<.04, \eta^{2}=.02$, and a main effect of performance-avoidance goal endorsement, $B=$ $0.14, F(1,199)=4.48, p<.04, \eta^{2}=.02$, were observed. When the target strongly endorsed these goals, he or she was perceived as more socially desirable ( $M=.17$ for mastery, $M=.17$ for performance-avoidance) than when he or she endorsed these goals weakly $(M=-.16$ for mastery, $M=-.18$ for performance- 
Table 5

Social Desirability and Social Utility of Mastery, Performance-Approach, and Performance-Avoidance Goal Endorsement (Experiment 3)

\begin{tabular}{|c|c|c|c|c|c|c|c|c|}
\hline \multirow[b]{3}{*}{ Goal endorsement } & \multicolumn{4}{|c|}{ Mastery (-) } & \multicolumn{4}{|c|}{ Mastery (+) } \\
\hline & \multicolumn{2}{|c|}{ Perf. approach $(-)$} & \multicolumn{2}{|c|}{ Perf. approach $(+)$} & \multicolumn{2}{|c|}{ Perf. approach (-) } & \multicolumn{2}{|c|}{ Perf. approach $(+)$} \\
\hline & $M$ & $S D$ & $M$ & $S D$ & $M$ & $S D$ & $M$ & $S D$ \\
\hline \multicolumn{9}{|c|}{ Social desirability } \\
\hline Perf. avoidance $(+)$ & 0.20 & 0.70 & -0.26 & 0.89 & 0.74 & 1.14 & 0.08 & 1.11 \\
\hline Perf. avoidance $(-)$ & -0.17 & 0.81 & -0.41 & 0.91 & 0.14 & 0.79 & -0.24 & 0.82 \\
\hline \multicolumn{9}{|c|}{ Social utility } \\
\hline Perf. avoidance $(+)$ & -0.43 & 0.75 & -0.67 & 0.56 & 0.49 & 0.83 & 0.80 & 0.82 \\
\hline Perf. avoidance $(-)$ & -0.56 & 0.95 & -0.34 & 0.78 & 0.26 & 0.65 & 0.60 & 0.70 \\
\hline
\end{tabular}

Note. (-) refers to the target's low endorsement of these goals; $(+)$ refers to the target's high endorsement of these goals.

avoidance). Of interest, the main effect of performance-approach goals was significant, $B=-0.21, F(1,199)=10.06, p<.002$, $\eta^{2}=.05$, but negative, showing that the target who strongly endorsed performance-approach goals was judged more negatively in term of social desirability $(M=-.21)$ than the target who endorsed these goals weakly $(M=.21)$. None of the interaction effects were significant (all $F s<1, \eta^{2}<.01$ ).

Social utility. Three main effects were significant. First, the main effect of coherence was significant and of a large size, $B=$ $0.17, F(1,199)=23.84, p<.001, \eta^{2}=.11$. This indicated that the more the target was perceived as coherent, the more he or she was judged high in social utility. More important, the main effect of performance-approach goals, $B=0.11, F(1,199)=4.28, p<$ $.04, \eta^{2}=.02$, indicated that the target who strongly endorsed performance-approach goals was judged higher on social utility $(M=.08)$ than the target who endorsed these goals to a lower extent $(M=-.08)$. The main effect of mastery goals, $B=0.48$, $F(1,199)=82.2, p<.001, \eta^{2}=.29$, also revealed that the target who strongly endorsed mastery goals was judged higher on social utility $(M=.55)$ than the target who endorsed these goals weakly $(M=-.50)$. There was no main effect of performance-avoidance goals $\left(B=-0.04, F<1, \eta^{2}<.01\right)$. As far as the interactions between goals are concerned, the only marginal interaction was the interaction between mastery and performance-approach goals, $B=$ $0.10, F(1,199)=3.31, p<.08, \eta^{2}=.02$. This interaction suggested that the positive effect of mastery goals on social utility was stronger when performance-approach goals were also high $(B=0.54)$ than when they were low $(B=0.38)$. Neither the other two-way interactions, $F<1, \eta^{2}<.01$, nor the three-way interaction, $B=0.06, F(1,199)=1.37, p=.24, \eta^{2}<.01$, reached significance.

\section{Discussion}

Consistent with what was observed in Experiments 1 and 2, the present experiment showed that the target who strongly endorsed mastery goals was perceived as both more likable (social desirability) and more likely to succeed (social utility) than the target who endorsed those goals weakly. We note that this latter effect is particularly large $\left(\eta^{2}=.29\right)$. Moreover, although this effect is smaller than for mastery goals, a target who strongly endorsed performance-approach goals was perceived as more likely to succeed (social utility) than a target who endorsed these goals weakly. However, this target was also perceived as less likable (social desirability) than the target who endorsed these goals weakly. These results replicated the findings of Experiment 2. Finally, a high level of performance-avoidance goal endorsement induced perceptions of the target as more likable (social desirability) than in the case of low endorsement but did not affect perceived likeliness to succeed (social utility). All the results observed in Experiment 2 are thus confirmed when the three goals vary at the same time. In general, the fact that no interaction was observed between different goals on social desirability suggests that these three main effects are independent of one another. Indeed, apart from the marginal interaction on social utility, which suggested that the target who strongly endorsed both mastery and performance-approach goals was perceived as more likely to succeed, no interaction reached significance.

\section{General Discussion}

These three experiments originated from the effort to understand how psychology university students cope with the ambivalence toward the promotion of different achievement goals that is inherent in a university context. More specifically, it was argued that in spite of the official discourse encouraging mastery goals but not performance goals (neither approach nor avoidance), the way the university functions values not only mastery goals but also performance-approach goals. Thus, it was hypothesized that students develop differential representations of reasons why different goals are valued. In particular, students were expected to perceive mastery goals as both socially desirable (because they are a way for the student to be judged as a nice person by their teachers) and socially useful (because they are a way for the student to be judged as competent and likely to succeed by their teachers). Moreover, performance-approach goals were expected not to be perceived as high in social desirability (because they are contrary to the official discourse), but still they were expected to be perceived as high in social utility, because in order to succeed in the university system, one has to get better grades than others, which implies the endorsement of performance-approach goals. Finally, on the basis of the results of the two pilot studies, and because of the high value associated with modesty (e.g., Schlenker \& Leary, 1982), 
predictions of performance-avoidance goals as high in perceived social desirability but not social utility were made.

Pilot Study 1 demonstrated that in their discourse, psychology teachers try to encourage mastery but not performance goals, neither approach nor avoidance, even though the latter are slightly more promoted than the former. The contribution of Pilot Study 2 was to indicate that despite this official discourse, students perceive that the three goals have some value at the university and that these effects are stronger for juniors than for freshmen. This second pilot study confirms that students become aware that both mastery and performance (approach and avoidance) goals are valued at the university.

More important, the three main experiments pointed out that these three goals are valued for different reasons. Mastery goals are highly valued in terms of both social desirability and social utility. Indeed, the more these goals are endorsed, the more the individual will be seen as likable and likely to succeed. This result appeared with the self-presentation paradigm (Experiment 1) as well as with the judge's paradigm (Experiments 2 and 3). This point can be considered as fairly positive, as it corresponds to both researchers' recommendations on the promotion of mastery goals and the teaching profession's general view of education. Pilot Study 1 showed how important it is for psychology teachers to promote the endorsement of such goals in their classes. These results confirm that students detect this recommendation.

Things are less straightforward for performance-approach goals. Indeed, as argued and confirmed in Pilot Study 1, teachers do not try to enhance these goals in their classes. However, university selection processes are apparent to students (they get graded, they have access to the statistics on failure, etc.), and they certainly know that to succeed in this system, one should be concerned not only with mastering but also with getting a good ranking and being better than others. Results of Experiments 1, 2, and 3 confirm this idea. Indeed, students appear to be aware of the fact that performance-approach goals are not valued in their teachers' discourse and that as a consequence, endorsing those goals to a high degree might make them appear as less likable than if they endorse those goals weakly. Hidi and Harackiewicz (2000) are in this sense probably right to consider these goals as "politically incorrect" (p. 169). What is particularly interesting is that in spite of that, students perceive performance-approach goals as a good indicator of university success. It seems, then, that whatever the official discourse, students are perfectly aware of what is actually required at the university, namely, not only progressing and learning (the educational function of the university) but also getting better ranks than their counterparts (the selection function of the university). What is also interesting to note is that students are actually fairly right in their predictions. Indeed, as mentioned earlier, many studies carried out in college classrooms show that performance-approach goals may indeed be a good predictor of academic achievement (e.g., Elliot \& McGregor, 1999, 2001; Harackiewicz et al., 1997, 2000, 2002; Pintrich, 2000; Skaalvik, 1997; Wolters, Yu, \& Pintrich, 1996; for a review, see Barron \& Harackiewicz, 2000, but see Darnon, Harackiewicz, Butera, Mugny, \& Quiamzade, 2007, for important moderators).

We finally note that as far as performance-avoidance goals are concerned, Pilot Study 2 indicates that support for these goals too is likely to increase when one wants to generate a positive image of oneself. Results obtained in Experiments 1, 2, and 3 suggest that this might be the case because these goals are valued in terms of social desirability but not in terms of social utility. However, Pilot Study 1 clearly indicated that teachers did not perceive themselves as trying to promote performance-avoidance goals in their classes. Thus, it seems that in spite of the fact that performance-avoidance goals are not actually encouraged by teachers, these goals still appear to be seen by students as high in social desirability. We have suggested that this could be due to a modesty effect. This interpretation is consistent with the fact that performanceavoidance goals are high in social desirability but not in social utility. However, other alternative explanations are possible. As an example, one could argue that performance-avoidance students may be viewed as less difficult and demanding compared with the sometimes overly demanding students who want to know exactly what they need to do to get a top grade, or students who want to learn more about the class. Thus, future research is needed in order to examine more specifically why performance-avoidance goals appear to be high in social desirability but not in social utility.

In this particular research program, psychology university students were examined. Would the results be the same in other educational structures (other universities, high schools, etc.)? One possibility is that every educational structure serves the two functions (education and selection) and that in this respect, the results would have basically been the same in any other educational structure. One could argue, however, that psychology majors present at least three peculiarities that make them different from students involved in other educational structures. First, as is the case in this particular set of studies, most psychology students are women. It is likely that performance-approach goals are less undesirable for men. Indeed, the stereotypical vision of a desirable woman is someone who is not competitive (King, Miles, \& Kniska, 1991). This could explain why men usually report endorsing performance-approach goals to a greater extent than women (e.g., Dweck, 1986; Régner, Escribe, \& Dupeyrat, 2007). Although gender does not seem to be a predictive factor of perceived social desirability and social utility (no effects of gender were observed in the present studies), the low number of male participants did not allow us to test this hypothesis in a conclusive way or to test for possible interactions between gender and goals. Thus, future research is needed to investigate whether the present findings would appear not only in the case of psychology students (a sample mainly composed of women) but also when dealing with students from different majors, notably those that include a larger number of men.

A second specificity of psychology majors is that they are usually characterized by a pronounced left-wing political orientation (Guimond, 2001; Guimond \& Palmer, 1996). Consequently, one could expect performance-approach goals to be less undesirable in other educational systems in which the idea of competition does not challenge the teacher's conception of education and political views so much. A final specificity of psychology majors, at least in France, is that psychology is the most chosen major because there is almost no selection at the university entrance level in this discipline (the only requirement is to have passed the high school final comprehensive exam). The result is a particularly large number of freshmen, which makes the selection process particularly salient. Maybe less selective educational structures would not, either in terms of social desirability or in terms of social utility, promote performance-approach goals. These ideas should 
be tested in future research, comparing educational structures that differ both in terms of their explicit discourse and ideology and in terms of their functioning (especially in the relative centrality and style of the selection processes).

In spite of the limitations, we believe that these results contribute to achievement goal research. First, these studies contribute to a better understanding of some results obtained in the achievement goal literature. In particular, there has been great debate about the effects of mastery goals on academic success. Early theory argued that mastery goals should predict academic success (e.g., Ames, 1992;Dweck, 1986), but recent research has challenged this idea (see Harackiewicz, Barron, \& Elliot, 1998; Harackiewicz et al., 2002). The present results underline that it might help to take into account the social context in which mastery and performance goals are examined. Indeed goal endorsement can strongly depend on the social functioning and dominant ideology of the educational system. The present results suggest that the way students answer an achievement goal questionnaire might not only depend on the students' personal goals but also reflect institutional constraints imposed on individuals by the educational system, and may therefore be the expression of self-presentation concerns. Classrooms are social contexts in which one may pursue not only achievementrelated goals but also social goals (see, e.g., Urdan, 1997; Wentzel, 2002). Trying to project a positive image of oneself can be one of these goals.

Obviously such a claim does not mean that personal goals play no part in goal measurements. In this respect, it is worth noting that in Pekrun et al.'s (2006) study, the effects of measured goals were maintained with social desirability being controlled for, suggesting that in spite of their high correlation to the social desirability scale, goals were still strong predictors of behavior. The present results nevertheless highlight a possible challenge for achievement goal theory. Indeed, they underline the fact that the answer one gives on an achievement goal questionnaire might reflect not only the goals one endorses but also the image one wants to convey to the teachers or the researchers. Future research will benefit from differentiating people who adopt achievement goals in a strategic way (to come across as nice and/or smart students) from those who do not. Such a distinction could perhaps be operationalized by using implicit measures of goals (as suggested by Pintrich, 2003) or by taking into account personality variables such as selfmonitoring (Gangestad \& Snyder, 2000) or normative clearsightedness (Somat \& Vazel, 1999). This could in turn help to clarify the relation between achievement goals and academic success and, in this way, provide a valuable contribution to the current debate about the effects of achievement goals.

Second, the present results could also explain why, in spite of researchers' recommendations and teachers' convictions, social comparison and competition are still so present and salient in our education system (Butler, 2005; J. M. Levine, 1983; see also Butler \& Kedar, 1990, and Harackiewicz et al., 1998, for a discussion of that point). They could also explain why teachers report having such difficulties in reducing performance-goal-related problems in their classes (Urdan, 1997, 2004; Urdan \& Turner, 2005). Over a decade ago, Blumenfeld (1992) mentioned how difficult it could be to implement mastery goals and discourage performance goals in the classroom. Notably, she questioned, "how can a mastery orientation be sustained in classrooms under circumstances in which absolute rather than improved performance has implications for placement, access to other courses, or future opportunities?" (p. 274; see also Urdan, 2004, for a similar discussion). In the same vein, Urdan (1997) reported the resistance he had observed from teachers. As he noted, many of them argue that "students and the larger community demand normative feedback" (p. 121). In a system in which normative comparison and getting better grades than others are so important and so decisive for one's future (Dubet \& Duru-Bellat, 2004), nobody can be blamed for being concerned with normative feedback. The present research shows that psychology students are aware of what is at stake. It also shows that they are able to use achievement goal endorsement (Experiment 1) and respond to the use of it (Experiments 2 and 3) in the pursuit of social desirability and social utility.

Do these results imply that teachers' and researchers' recommendations should be more "honest" or "realistic" and promote performance-approach goals in addition to mastery goals, instead of discouraging them? The answer might be that it depends on what teachers really want to do in their classes. If one thinks that university is designed to select, then one should recognize the adaptive function of performance-approach goals in such a system, avoid hypocritical discourse about these goals, and stop denigrating students who endorse such goals. However, in light of the potential negative consequences of performance-approach goal endorsement (for reviews, see Ames, 1992; Dweck, 1986; Pintrich \& Schunk, 2002), this solution is probably not the best one for students. Rather, if one thinks that the function of the university should not be to select but only to teach, to help all students construct knowledge and increase their skills by applying a sort of "no student left behind" ideology, then one should be particularly attentive to the ambivalence of the functioning of the university system. Unlike Urdan and Turner (2005), we do not think it is necessary to teach and convince teachers of the fact that they should promote mastery goals and avoid performance goals in their classes (see also Urdan, 2004). At least in a psychology major, the first pilot study indicated that teachers are perfectly aware of what they should do. Rather, this research underlines the necessity, if one really wants to reduce the underlying utility of performance-approach goals at university, to question institutional functioning rather than teachers' practices. In line with Duru-Bellat (2006), we exhort educational structures to make a clear distinction between the function of education and that of selection. As an example, it should be clear when students are asked to perform (e.g., during exams) and when they are asked to learn (the rest of the time).

The present results show that students are clearly able to recognize that different goals should be endorsed in different situations for different purposes. A major challenge for future research would be, in this sense, to examine and test structures that, in their functioning, do not imply covert selection. Only in such contexts would the discourse encouraging mastery goals and discouraging performance goals make real sense and come across as legitimate to students.

\section{References}

Ames, C. (1984). Achievement attributions and self-instructions under competitive and individualistic goal structures. Journal of Educational Psychology, 76, 478-487.

Ames, C. (1992). Classrooms: Goals, structures, and student motivation. Journal of Educational Psychology, 84, 261-271.

Ames, C., \& Felker, D. W. (1979). An examination of children's attributions and achievement-related evaluations in competitive, cooperative, and individualistic reward structures. Journal of Educational Psychology, 71, 413-420. 
Arrow, K. (1973). Higher education as a filter. Journal of Public Economics, 2, 193-216.

Barron, K., \& Harackiewicz, J. M. (2000). Achievement goals and optimal motivation: A multiple goals approach. In C. Sansone \& J. M. Harackiewicz (Eds.), Intrinsic and extrinsic motivation: The search for optimal motivation and performance (pp. 229-254). San Diego, CA: Academic Press.

Barron, K., \& Harackiewicz, J. M. (2001). Achievement goals and optimal motivation: Testing multiple goal models. Journal of Personality and Social Psychology, 80, 706-722.

Beauvois, J. L. (2003). Judgment norms, social utility, and individualism. In N. Dubois (Ed.), A sociocognitive approach to social norms (pp. 123-147). London: Routledge.

Blumenfeld, P. C. (1992). Classroom learning and motivation: Clarifying and expanding goal theory. Journal of Educational Psychology, 84, 272-281.

Bourdieu, P., Passeron, J. C., \& Nice, J. P. (1990). Reproduction in education, society and culture. London: Sage.

Brophy, J. (2004). Motivating students to learn. Mahwah, NJ: Erlbaum.

Brophy, J. (2005). Goal theorists should move on from performance goals. Educational Psychologist, 40, 167-176.

Butler, R. (1987). Task-involving and ego-involving properties of evaluation: Effects of different feedback conditions on motivational perceptions, interest and performance. Journal of Educational Psychology, 79, 474-482.

Butler, R. (2005). Competence assessment, competence, and motivation between early and middle childhood. In A. J. Elliot \& C. S. Dweck (Eds.), Handbook of competence and motivation (pp. 202-221). New York: Guilford Press.

Butler, R. (2006). Are mastery and ability goals both adaptive? Evaluation, initial goal construction and the quality of task engagement. British Journal of Educational Psychology, 76, 595-611.

Butler, R., \& Kedar, A. (1990). Effects of inter-group competition and school philosophy on motivational perceptions, group process and performance. Contemporary Educational Psychology, 15, 301-318.

Butler, R., \& Nisan, M. (1986). Effects of no feedback, task-related comments, and grades on intrinsic motivation and performance. Journal of Educational Psychology, 78, 210-216.

Cambon, L. (2002). Désirabilité et utilité sociale, deux composantes de la valeur. Une exemplification dans l'analyse des activités professionnelles [Desirability and social utility, two components of value. An exemplification in the analysis of occupational activities]. L'Orientation Scolaire et Professionnelle, 31, 75-96.

Cambon, L., Djouari, A., \& Beauvois, J.-L. (2006). Social judgment norms and social utility: When it is more valuable to be useful than desirable. Swiss Journal of Psychology, 65, 167-180.

Covington, M. V. (1992). Making the grade: A self-worth perspective on motivation and school reform. New York: Cambridge University Press.

Covington, M. V., \& Omelich, C. L. (1984). Task-oriented versus competitive learning structures: Motivational and performance consequences. Journal of Educational Psychology, 76, 1038-1050.

Darnon, C., \& Butera, F. (2005). Buts d'accomplissement, stratégies d'étude, et motivation intrinsèque: Présentation d'un domaine de recherche et validation française de l'échelle d'Elliot et McGregor (2001) [Achievement goals, study strategies, and intrinsic motivation: Presenting a domain of research and the French validation of Elliot and McGregor's (2001) scale]. L'Année Psychologique, 105, 105-131.

Darnon, C., Butera, F., \& Harackiewicz, J. M. (2007). Achievement goals in social interactions: Learning with mastery vs. performance goals. Motivation and Emotion, 31, 61-70.

Darnon, C., Harackiewicz, J. M., Butera, F., Mugny, G., \& Quiamzade, A. (2007). Performance-approach and performance-avoidance goals: When uncertainty makes a difference Personality and Social Psychology Bulletin, 33, 813-827.
Darnon, C., Muller, D., Schrager, S. M., Pannuzzo, N., \& Butera, F. (2006). Mastery and performance goals predict epistemic and relational conflict regulation. Journal of Educational Psychology, 98, 766-776.

Deutsch, M. (1979). Education and distributive justice: Some reflections on grading systems. American Psychologist, 34, 391-401.

Devos-Comby, L., \& Devos, T. (2001). Social norms, social value, and judgments of responsibility. Swiss Journal of Psychology, 60, 35-46.

Dompnier, B., Pansu, P., \& Bressoux, P. (2007). Social utility, social desirability and scholastic judgments: Toward a personological model of academic evaluation. European Journal of Psychology of Education, 22, $335-352$.

Dubet, F., \& Duru-Bellat, M. (2004). Qu'est-ce qu'une école juste? [What is a fair school?] Revue Française de Pédagogie, 146, 105-114.

Dubois, N. (2000). Self-presentation strategies and social judgments: Desirability and social utility of causal explanations. Swiss Journal of Psychology, 59, 170-182.

Dubois, N., \& Beauvois, J. L. (2005). Normativeness and individualism. European Journal of Social Psychology, 35, 123-146.

Duru-Bellat, M. (1996). Social inequalities in French secondary schools: From figures to theories. British Journal of Sociology of Education, 17, 341-351.

Duru-Bellat, M. (2006). L'inflation scolaire. Les désillusions de la méritocratie [The school inflation. Disillusions of meritocracy]. Paris: Seuil.

Dweck, C. S. (1986). Motivational processes affecting learning. American Psychologist, 41, 1040-1048.

Dweck, C. S. (1992). The study of goals in psychology. Psychological Science, 3, 165-167.

Dweck, C. S. (1999). Self-theories: Their role in motivation, personality and development. Philadelphia: Psychology Press.

Dweck, C. S., \& Sorich, L. A. (1999). Mastery-oriented thinking. In C. R. Snyder (Ed.), Coping (pp. 232-251). New York: Oxford University Press.

Elliot, A. J. (1997). Integrating the "classic" and "contemporary" approaches to achievement motivation: A hierarchical model of approach and avoidance motivation. In M. Maehr \& P. Pintrich (Eds.), Advances in motivation and achievement (Vol. 10, pp. 143-179). Greenwich, CT: JAI Press.

Elliot, A. J. (1999). Approach and avoidance motivation and achievement goals. Educational Psychologist, 34, 169-189.

Elliot, A. J., \& Church, M. A. (1997). A hierarchical model of approach and avoidance achievement motivation. Journal of Personality and Social Psychology, 72, 218-232.

Elliot, A. J., \& Harackiewicz, J. M. (1996). Approach and avoidance achievement goals and intrinsic motivation: A mediational analysis. Journal of Personality and Social Psychology, 70, 461-475.

Elliot, A. J., \& McGregor, H. A. (1999). Test anxiety and the hierarchical model of approach and avoidance achievement motivation. Journal of Personality and Social Psychology, 76, 628-644.

Elliot, A. J., \& McGregor, H. A. (2001). A $2 * 2$ achievement goal framework. Journal of Personality and Social Psychology, 80, 501-519.

Fiske, S. T., Cuddy, A. J. C., Glick, P., \& Xu, J. (2002). A model of (often mixed) stereotype content: Competence and warmth respectively follow from perceived status and competition. Journal of Personality and Social Psychology, 82, 878-902.

Gangestad, S. W., \& Snyder, M. (2000). Self-monitoring: Appraisal and reappraisal. Psychological Bulletin, 126, 530-555.

Gilibert, D., \& Cambon, L. (2003). The paradigms and their contributions. In N. Dubois \& J. L. Beauvois (Eds.), A sociocognitive approach to social norms (pp. 38-69). London: Routledge.

Green, E. G. T. (2006). Successful or friendly? Inferring achievement and relational competence from individualist and collectivist attitudes. Swiss Journal of Psychology, 65, 25-36.

Guimond, S. (2001). Epistemic authorities in higher education: The relative influence of peers, faculty and courses on attitude formation and change. 
In F. Butera \& G. Mugny (Eds.), Social influence in social reality (pp. 211-223). Göttingen, Germany: Hogrefe \& Huber.

Guimond, S., \& Palmer, D. L. (1996). The political socialization of commerce and social science students: Epistemic authority and attitude change. Journal of Applied Social Psychology, 26, 1985-2013.

Harackiewicz, J. M., Barron, K. E., Carter, S. M., Lehto, A. T., \& Elliot, A. J. (1997). Predictors and consequences of achievement goals in the college classroom: Maintaining interest and making the grade. Journal of Personality and Social Psychology, 73, 1284-1295.

Harackiewicz, J. M., Barron, K. E., \& Elliot, A. J. (1998). Rethinking achievement goals: When are they adaptive for college students and why? Educational Psychologist, 33, 1-21.

Harackiewicz, J. M., Barron, K. E., Pintrich, P. R., Elliot, A. J., \& Thrash, T. M. (2002). Revision of achievement goal theory: Necessary and illuminating. Journal of Educational Psychology, 94, 638-645.

Harackiewicz, J. M., Barron, K. E., Tauer, J. M., Carter, S. M., \& Elliot, A. J. (2000). Short-term and long-term consequences of achievement goals: Predicting interest and performance over time. Journal of Educational Psychology, 92, 316-330.

Hareli, S., \& Weiner, B. (2000). Accounts for success as determinants of perceived arrogance and modesty. Motivation and Emotion, 24, 215-236.

Heatherington, L., Crown, J., Wagner, H., \& Rigby, S. (1989). Toward an understanding of social consequences of "feminine immodesty" about personal achievements. Sex Roles, 20, 371-380.

Hidi, S., \& Harackiewicz, J. M. (2000). Motivating the academically unmotivated: A critical issue for the 21st century. Review of Educational Research, 70, 151-179.

Jellison, J. M., \& Green, J. (1981). A self-presentation approach to the fundamental attribution error: The norm of internality. Journal of Personality and Social Psychology, 40, 643-649.

Judd, C. M., James-Hawkins, L., Yzerbyt, V., \& Kashima, Y. (2005). Fundamental dimensions of social judgments: Understanding the relations between judgments of competence and warmth. Journal of Personality and Social Psychology, 89, 899-913.

Judd, C. M., \& McClelland, G. H. (1989). Data analysis: A model comparison approach. San Diego, CA: Harcourt, Brace, Jovanovich.

Kaplan, A. (2004). Achievement goals and intergroup relations. In P. R. Pintrich \& M. L. Maehr (Eds.), Advances in research on motivation and achievement: Vol. 13. Motivating students, improving schools: The legacy of Carol Midgley (pp. 97-136). Oxford, England: Elsevier.

King, W. C., Miles, E. W., \& Kniska, J. (1991). Boys will be boys (and girls will be girls): The attribution of gender role stereotypes in a gaming situation. Sex Roles, 25, 607-623.

Lamarche, T. (2006). L'éducation, un secteur économique en construction? [Education, an economic field under construction?]. In T. Lamarche (Ed.), Capitalisme et éducation (pp. 11-25). Paris: Syllepse.

Le Barbenchon, E., Cambon, L., \& Lavigne, F. (2005). Désirabilité et utilité sociale de 308 adjectifs et 297 professions [Desirability and social utility of 308 adjectives and 297 occupations]. L'Année Psychologique, 105, 317-355.

Levine, J. M. (1983). Social comparison and education. In J. M. Levine \& M. C. Wang (Eds.), Teacher and student perception: Implications for learning (pp. 29-55). Hillsdale, NJ: Erlbaum.

Levine, R. V., \& West, L. J. (1976). Attraction as a function of boasting, self-apology, and credibility as an actor. Psychological Reports, 38, $1243-1246$

Maehr, M. L., \& Midgley, C. (1991). Enhancing student motivation: A schoolwide approach. Educational Psychologist, 26, 399-427.

Meece, J. L., Anderman, E. M., \& Anderman, L. H. (2006). Classroom goal structure, student motivation and academic achievement. Annual Review of Psychology, 57, 487-503.

Midgley, C., \& Urdan, T. (2001). Academic self handicapping and achievement goals: A further examination. Contemporary Educational Psychology, 26, 61-75.

Muller, D., \& Butera, F. (2004). On being concerned about bragging. Current Psychology of Cognition, 22, 159-179.

Muller, D., Yzerbyt, V., \& Judd, C. M. (2008). Adjusting for a mediator in models with two crossed treatment variables. Organizational Research Methods, 11, 224-240.

Nicholls, J. G. (1984). Achievement motivation: Conceptions of ability, subjective experience, task choice, and performance. Psychological Review, 91, 328-346.

Nicholls, J. G. (1989). The competitive ethos and democratic education. Cambridge, MA: Harvard University Press.

OECD. (2006). Education at a glance. OECD indicators. 2006. Paris: OECD Publishing.

Osgood, C. E. (1962). Studies on the generality of affective meaning systems. American Psychologist, 17, 10-28.

Osgood, C. E. (1969). On the whys and wherefores of E, P, and A. Journal of Personality and Social Psychology, 12, 194-199.

Osgood, C. E., Suci, G. J., \& Tannenbaum, P. H. (1957). The measurement of meaning. Urbana: University of Illinois Press.

Peeters, G. (1992). Evaluative meaning of adjectives in vitro and in context: Some theoretical implications and practical consequences of positive-negative asymmetry and behavioral-adaptative concepts of evaluation. Psychologica Belgica, 32, 211-231.

Peeters, G. (2002). From the good and the bad to can and must: Subjective necessity of acts associated with positively and negatively valued stimuli. European Journal of Social Psychology, 32, 125-136.

Pekrun, R., Elliot, A. J., \& Maier, M. A. (2006). Achievement goals and discrete achievement emotions: A theoretical model and prospective test. Journal of Educational Psychology, 98, 583-597.

Pintrich, P. (2000). Multiple goals, multiple pathways: The role of goal orientation in learning and achievement. Journal of Educational Psychology, 92, 544-555.

Pintrich, P. (2003). A motivational science perspective on the role of student motivation in learning and teaching contexts. Journal of Educational Psychology, 95, 667-686.

Pintrich, P., \& Schunk, D. (2002). Motivation in education: Theory, research, and applications (2nd ed.). Upper Saddle River, NJ: Merrill Prentice-Hall.

Reeder, G. D., \& Brewer, M. B. (1979). A schematic model of dispositional attribution in interpersonal perception. Psychological Review, 86, $61-79$.

Régner, I., Escribe, C., \& Dupeyrat, C. (2007). Evidence of social comparison in mastery goals in natural academic settings. Journal of Educational Psychology, 99, 575-583.

Rosenberg, S., Nelson, C., \& Vivekananthan, P. S. (1968). A multidimensional approach to the structure of personality impressions. Journal of Personality and Social Psychology, 9, 282-294.

Rosenberg, S., \& Sedlak, A. (1972). Structural representations of implicit personality theory. In L. Berkowitz (Ed.), Advances in experimental social psychology (Vol. 6, pp. 235-297). New York: Academic Press.

Schlenker, B. R., \& Leary, M. R. (1982). Audiences' reactions to selfenhancing, self-denigrating, and accurate self-presentations. Journal of Experimental Social Psychology, 18, 89-104.

Skaalvik, E. M. (1997). Self-enhancing and self-defeating ego orientation: Relations with task and avoidance orientation, achievement, self-perceptions, and anxiety. Journal of Educational Psychology, 89, 71-81.

Somat, A., \& Vazel, M. A. (1999). Normative clearsightedness: A general knowledge of social valuation. European Journal of Social Psychology, 29, 691-705.

Tice, D. M., Butler, J. L., Muraven, M. B., \& Stillwell, A. M. (1995). When modesty prevails: Differential favorability of self-presentation to friends 
and strangers. Journal of Personality and Social Psychology, 69, 11201138.

Urdan, T. (1997). Achievement goal theory: Past results, future directions. In M. Maehr \& P. Pintrich (Eds.), Advances in motivation and achievement (Vol. 10, pp. 99-141). Greenwich, CT: JAI Press.

Urdan, T. (2004). Can achievement goal theory guide school reform? In P. R. Pintrich \& M. L. Maehr (Eds.), Advances in motivation and achievement (Vol. 13, pp. 361-392). Stanford, CA: JAI Press.

Urdan, T., \& Turner, J. C. (2005). Competence motivation in the classroom. In A. J. Elliot \& C. S. Dweck (Eds.), Handbook of competence and motivation (pp. 297-317). New York: Guilford Press.

Van Yperen, N. W. (2006). A novel approach to assessing achievement goals in the context of the $2 \times 2$ framework: Identifying distinct profiles of individuals with different dominant achievement goals. Personality and Social Psychology Bulletin, 32, 1432-1445.

Vonk, R. (1993). Individual differences and common dimensions in implicit personality theory. British Journal of Social Psychology, 32, 209-226.

Wentzel, K. R. (2002). The contribution of social goal setting to children's school adjustment. In A. Wigfield \& J. Eccles (Eds.), Development of motivation (pp. 221-246). New York: Academic Press.

Wiggins, J. S. (1979). A psychological taxonomy of trait-descriptive terms:
The interpersonal domain. Journal of Personality and Social Psychology, 37, 395-412.

Wojciszke, B. (1997). Parallels between competence versus morality related traits and individualistic versus collectivistic values. European Journal of Social Psychology, 27, 245-256.

Wojciszke, B. (2005). Morality and competence in person- and selfperception. In W. Stroebe \& M. Hewstone (Eds.), European review of social psychology (Vol. 16, pp. 155-188). New York: Taylor \& Francis.

Wolters, C. A., Yu, S. L., \& Pintrich, P. R. (1996). The relation between goal orientation and students' motivational beliefs and self-regulated learning. Learning and Individual Differences, 8, 211-238.

Wosinska, W., Dabul, A. J., Whetstone-Dion, R., \& Cialdini, R. B. (1996). Self-presentational responses to success in the organization: The costs and benefits of modesty. Basic and Applied Social Psychology, 18, $229-242$.

Yzerbyt, V., Muller, D., \& Judd, C. M. (2004). Adjusting researchers' approach to adjustment: On the use of covariates when testing interactions. Journal of Experimental Social Psychology, 40, 424-431.

Received June 19, 2007

Revision received February 29, 2008

Accepted May 16, 2008

\section{Correction to Weber and Murnighan (2008)}

In the article "Suckers or Saviors? Consistent Contributors in Social Dilemmas," by J. Mark Weber and J. Keith Murnighan (Journal of Personality and Social Psychology, 2008, Vol. 95, No. 6, pp. 1340-1353), an incorrect DOI was printed. The correct DOI is a0012454.

DOI: $10.1037 / a 0014765$ 